\title{
Theoretical and Practical Considerations of the Newer Methods of the European Pharmacopeia for the Assay of Halide Salts of Organic Bases
}

\author{
Ragnar Bye, University of Oslo, Department of Pharmacy, P.O. Box 1068,
} N-0316 Oslo, Norway. E-mail: ragnar.bye@farmasi.uio.no

\section{INTRODUCTION}

A certain type of titration methods have appeared with an increasing frequency during the last years, this being evident surveying the latest editions of the European Pharmacopeia (19972001) [1-3], where there are now more than fifty monographs on the assay of halide salt of organic bases by potentiometric titration of the sample dissolved in ethanol or in an ethanolwater mixture with sodium hydroxide after addition of a defined volume of diluted hydrochloric acid.

These new methods are obviously intended to be replacements of the widely used nonaqueous perchloric acid titrations, as the highly unwanted addition mercuric acetate normally was included in these methods.

However, as the new methods, now being more and more established, are based on principles that were quite questionable to the present author - both from a theoretical and a practical point of view - it was decided to undertake some investigations in order to attempt to assess the possible advantages of the new official methods for assay of halide salts of organic bases involving the addition of hydrochloric acid.

In addition to the presentation and discussion of the experimental details and results, some relevant theoretical aspects of the new methods are discussed as.

\section{EXPERIMENTAL}

\section{Equipment and materials}

An Orion model $720 \mathrm{~A} \mathrm{pH}$-meter equipped with a combined $\mathrm{pH} /$ reference electrode was used for all measurements. The instrument was calibrated according to the manufacturer's procedure.

$0.1 \mathrm{M} \mathrm{NaOH}$ and $0.1 \mathrm{M} \mathrm{HCl}$ were made according to standard procedures [1]. $0.01 \mathrm{M} \mathrm{HCl}$ was made by diluting the $0.1 \mathrm{M}$ solution ten times. In order to obtain the exact concentration of the $0.1 \mathrm{M}$ sodium hydroxide solution, it was standardized against potassium hydrogenphtalate using phenolphtalein as indicator.

The following compounds, all obtained from Sigma (USA), were analyzed: Hydrochlorides of Alprenolol, Amantadine, Bromhexine, Chlorpromazine, Cyclopentanolate, Lidocaine and Promethazine.

\section{Procedures}

The official Pharmacopoeia method:

According to the procedure given in the actual monograph, the hydrochloride samples were dissolved as follows: For Alprenolol (method 1997:0876): $0.400 \mathrm{~g}$ in $10 \mathrm{ml}$ of $0.01 \mathrm{M} \mathrm{HCl}$ and $25 \mathrm{ml}$ of ethanol/water (1+1); for Amantadine (1997:0463), Chlorpromazine (1997:0475), Lidocaine (1997:0227) and Promethazine (197:0524): $0.150-0.250-0.250$ and 0.250 gram in $5 \mathrm{ml}$ of $0.01 \mathrm{M} \mathrm{HCl}$ and $50 \mathrm{ml}$ of ethanol; for Bromhexine (1997:0706) and Cyclopentolate (1997:1093): 0.300 and 0.250 gram in $1 \mathrm{ml}$ of $0.1 \mathrm{M} \mathrm{HCl}$ and $70 \mathrm{ml}$ and $50 \mathrm{ml}$ of ethanol, respectively.

The solutions were titrated potentiometrically with $0.1 \mathrm{M}$ of sodium hydroxide (with exact 
known concentration). The titration curve was constructed and the consumed volume of $\mathrm{NaOH}$ between the two points of inflexion of the respective titration curves was measured and used (together with the exact concentration of $\mathrm{NaOH}$ ) for the calculation of the results.

Alternative method, omitting the addition of $\mathrm{HCl}$ :

As above, except that instead of the prescribed volume of $\mathrm{HCl}$, an identical volume of water was added. The consumed volume of sodium hydroxide was recorded at the point of inflexion of the titration curve; in this case only one point of inflexion had to be considered.

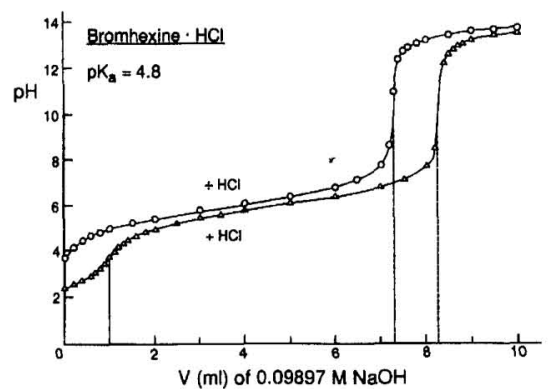

Figure 1.

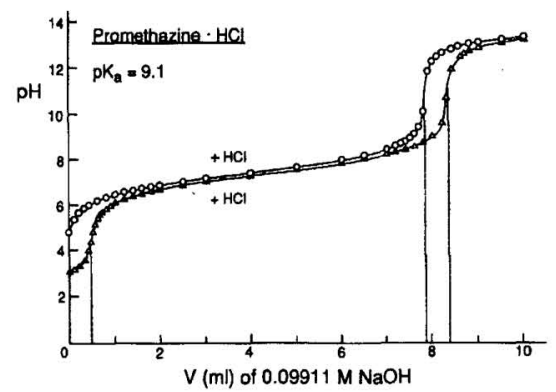

Figure 3.

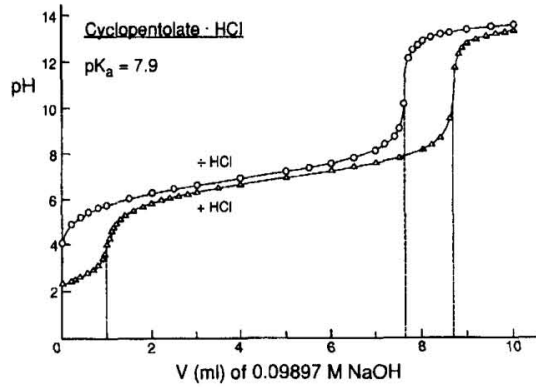

Figure 2.

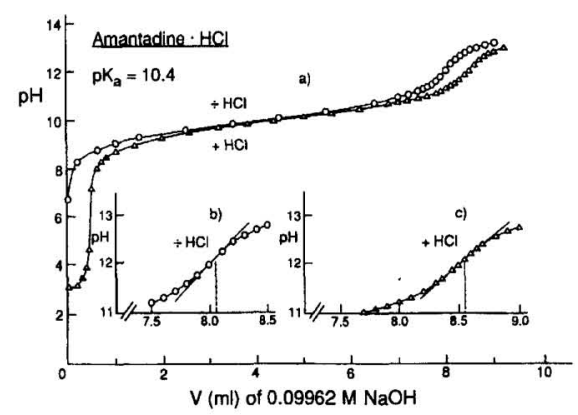

Figure 4.

\section{RESULTS}

The content limits given in Pharm. Eur. for the assay of the investigated compounds are given in Table 1 , as well as the $\mathrm{pK}_{\mathrm{a}}$-values for the acids (the protonated bases). In the same table the obtained results with and without added $\mathrm{HCl}$ are given. As is evident from the the table, both versions of the methods gave results that were consistent with each other. Six of the results (for both methods) were within the demanded limits, whereas for one of the compounds the results (for both methods) was slightly lower. The titration curves (both versions) are presented for the hydrochlorides of Bromhexine, Cyclopentolate, Promethazine and Amantadine (Figs. 1-4) Fig. 4. (for Amantadine hydrochloride) also includes a magnification of the two curves at the second inflexion point). 
In order to assess the precision of the $\mathrm{HCl}$-omitting version, eight parallells of Promethazine hydrochloride were titrated as described above. The obtained relative standard deviation of the method was 0.34 ; this value being very similar to those obtained for the $\mathrm{HCl}$-including methods [4].

Table 1: Assay of hydrochlorides of some organic bases (means of duplicate)

\begin{tabular}{lcccc}
\hline & & \multicolumn{2}{c}{ Results (\%) } \\
Substance & $\left.\mathbf{p K}_{\mathbf{a}} \mathbf{x}\right)$ & Limits (\%) & With HCl & Without HCl \\
\hline Alprenolol & 9.5 & $99.0-101.0$ & 100.2 & 100.8 \\
Amantadine & 10.4 & $98.5-101.0$ & 100.7 & 100.4 \\
Bromhexine & 4.8 & $98,5-101.5$ & 99.4 & 100.1 \\
Chlorpromazine & 9.3 & $99.0-101.0$ & 98.0 & 98.7 \\
Cyclopentolate & 7.9 & $98.5-101.5$ & 99.2 & 99.5 \\
Lidocaine & 8.1 & $99.0-101.0$ & 99.4 & 99.7 \\
Promethazine & 9.1 & $99.0-101.0$ & 100.2 & 100.0 \\
& \\
X) From Reference [5], except for Bromhexine and Lidocaine for which the values have \\
determined in this work.
\end{tabular}

\section{DISCUSSION}

In discussing the principles of the methods some chemical reactions and equilibria should be considered. As the $\mathrm{pK}_{\mathrm{a}}$-values for most of the examined protonated bases (i.e. acids) were 810.5 , these can hardly be titrated potentiometrically when dissolved in water only. However, because ethanol, having a much smaller constant of autoprotolysis than water $\left(3 \cdot 10^{-20}\right.$ relative to $1 \cdot 10^{-14}$ ), is the major constituent of the solvent, the equilibrium constant of the titration reaction [Eq. (4)] is increased [6], making the titration much more feasible when the salt is dissolved in ethanol or etanol/water, whether or not $\mathrm{HCl}$ is added from the beginning.

In discussing the purpose of the addition of $\mathrm{HCl}$ the following reactions must be considered; the first one describing the process taking place when the compound is dissolved

$$
\mathrm{AHCl} \underset{\mathrm{H}_{2} \mathrm{O}}{\stackrel{\mathrm{EtOH}}{\rightarrow}} \mathrm{AH}^{+}+\mathrm{Cl}^{-}
$$

And the equilibria for the acid, $\mathrm{AH}^{+}$:

$$
\mathrm{AH}^{+}+\mathrm{H}_{2} \mathbf{O} \leftrightarrows \mathrm{H}_{3} \mathbf{O}^{+}+\mathbf{A}
$$

and/or

$$
\mathrm{AH}^{+}+\mathrm{C}_{2} \mathrm{H}_{5} \mathrm{OH} \leftrightarrows \mathrm{C}_{2} \mathrm{H}_{5} \mathrm{OH}_{2}^{+}+\mathrm{A}
$$

The first of these reactions describes the dissolution process, not being an equilibrium since the compound is completely dissolved. An addition of $\mathrm{HCl}$ will definitely not increase the solubility and is hence of no interest in this context. Inspecting equilibria (2) and (3) it might be suspected that an addition of $\mathrm{HCl}$, i.e. of $\mathrm{H}_{3} \mathrm{O}^{+}$, will result in that the "sample" acid would become weaker because such an addition should force the equilibria towards the left. However, 
after the first equivalence point, i.e. when $\mathrm{H}_{3} \mathrm{O}^{+}$from $\mathrm{HCl}$ has been titrated, the solution will behave as if $\mathrm{HCl}$ never has been added. This implies that the acid constant $\left(\mathrm{K}_{\mathrm{a}}\right)$ of the actual acid in the particular solute will now be almost the same as if $\mathrm{AH}^{+}$was the only acid in the particular solute. This further implies that the equilibrium constant of the titration, $\mathrm{K}_{\mathrm{titr} \text {., }}$

$$
\mathrm{AH}^{+}+\mathrm{OH}^{-} \rightleftharpoons \mathrm{A}+\mathrm{H}_{2} \mathrm{O}
$$

in the particular solvent should be almost the same whether or not $\mathrm{HCl}$ was added. As a consequence, the same change in $\mathrm{pH}$ at the equivalence point should be expected in absence of $\mathrm{HCl}$. Accordingly, the addition of $\mathrm{HCl}$ should have no possitive effect as to the confidence of the final equivalence point, because the addition of $\mathrm{HCl}$ will not make the inflexion point for the "sample" acid more distinct. On the contrary, it will be somewhat less so, as can be seen from the figures and particularly from Fig. 4 . in which the vicinities of the equivalence points in the titrations of Amantadine hydrochloride by both methods have been magnified.

Moreover, the figures also show that the evaluation of the first equivalence point by means of visual inspection of the titration curve could be rather difficult: The stronger the sample acid is, the more difficult is it to evaluate the equivalence point for the $\mathrm{HCl}$ titration accurately (Fig. 1). Likewise, if the sample acid is very weak (for instance Amantadine - Fig. 4.), its equivalence point can hardly be visually determined with the desired accuracy (no matter whether $\mathrm{HCl}$ has been added or not). Generally, in order to determine the sample titation volume with the best possible accuracy, it should in fact have been better if the amount of the added $\mathrm{HCl}$ had been larger than the prescribed in order to make the first vertical part of the titation curve larger. In this way a visual (geometrical) evaluation of the first inflexion point would have become easier and more accurate.

It might certainly be objected that both equivalence points can be determined accurately by solving the second derivative equation for the titration data, i.e. determining the titration volume when $\Delta^{2} p H / \Delta V^{2}=0$ (in that case a construction of the titration curve will not be necessary). However, such an operation is hardly intended for a successful practical outcome of these methods.

What was then the original argument for introducing the addition of $\mathrm{HCl}$ in these methods? In discussing this it is necessary to consult references [6] and [7]. In these the following statement is of importance: "Since some salts are produced by the action of gaseous acid on the base, halide acid may be present in the final product in which case falsely high assay results may be obtained when the substance is titrated directly. By adding a small amount of $\mathrm{HCl}$ in the titration medium such errors can be avoided by determining the volume between the two inflexion points" [7]. This statement is in principle correct. However, the probability that such type of products contaminated with residual halide acid are launched on the pharmaceutical market is very small. The main reason for this is: If acid-contaminated salts are tested according to the methods given in Pharm Eur., they will certainly not comply with the "acidity/alkalinity test" given for almost all of these salts. And as this test is carried out prior to the assay titration, the titration will not be performed.

\section{CONCLUSIONS}

Because the results of the titrimetric assay of the investigated hydrochlorides of organic bases omitting the prescribed additions of hydrochloric acid are as confident as those obtained when analyzing the compounds according to the official monographs that include the addition of hydrochloric acid, this author suggests that the addition should be omitted for the following reasons: 
1. Fewer reagent solutions will be required.

2. Saving of time and labour.

3. The methods should be intelligible both from a theoretical and a practical point of view; this being of general importance and especially for the introduction of such methods to students.

Any possible advantages of the official methods, relative to those omitting the addition of hydrochloric acid, have not been found.

\section{REFERENCES}

[1] European Pharmacopeia, $3^{\text {rd }}$ ed.(1997), Council of Europe, Strasbourg

[2] European Pharmacopeia, $3^{\text {rd }}$ ed. Suppl. (2000), Council of Europe, Strasbourg

[3] European Pharmacopeia, $3^{\text {rd }}$ ed. Suppl. (2001), Council of Europe, Strasbourg

[4] Miller, J.H. McB. (1989), J. Pharm. Biomed. Anal. 7: 771

[5] Martindale, $30^{\text {th }}$ ed. (1993), The Pharmaceutical Press London

[6] Skoog, D.A., West, D.M. and Holler, F.J. (1988), Fundamentals in Analytical Chemistry, $5^{\text {th }}$ ed., Saunders College Publishing, New York, pp. 245-250

[7] Miller, J.H.McB. (1996), Pharmeuropa. 8: 400 